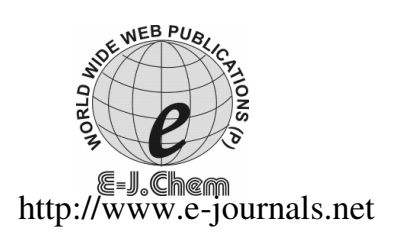

ISSN: 0973-4945; CODEN ECJHAO

E-Journal of Chemistry

2011, 8(3), 1424-1429

\title{
Development and Validation of a Rapid RP HPLC Method for the Determination of Cinitapride Hydrogen Tartarate in Solid Oral Dosage Forms
}

\author{
SYEDA HUMAIRA ${ }^{\# *}$, AKALANKA DEY", \\ S.APPALA RAJU ${ }^{\S}$ and SYED SANAULLAH \\ \#Department of Pharmacy, Annamalai University \\ Chidambaram, Tamilnadu, India \\ ${ }^{\S}$ H.K.E's College of Pharmacy \\ Sedam Road, Gulbarga, Karnataka, India \\ Luqman College of Pharmacy, Behind P \& T Quarters \\ Old jewargi Road, Gulbarga, India \\ sanashs@rediffmail.com
}

Received 8 June 2010; Accepted 27 August 2010

\begin{abstract}
In the present study a simple, sensitive rapid and accurate HPLC method with UV detection for the analysis of cinitapride hydrogen tartarate was developed and validated in solid dosage forms. The method utilized gradient elution technique with C18 column (150x4.6 mm I.D, $5 \mu \mathrm{m}$ particle size) with mobile phase consisting of $0.1 \%$ formic acid in water and acetonitrile The detection wavelength was at $268 \mathrm{~nm}$, with flow rate of $0.5 \mathrm{~mL} / \mathrm{min}$ and injection volume of $10 \mu \mathrm{L}$ for separation of cinitapride in bulk drugs and pharmaceutical formulations. The gradient elution was developed for better and optimized results. The developed method was validated for precision which includes system precision and method precision, accuracy and linearity studies in the concentration range of $5-100 \mu \mathrm{g} / \mathrm{mL}$ with correlation coefficient of 0.9987 . The accuracy (recovery) was between 97.32 and $100.82 \%$. The proposed method is simple, fast, accurate, precise and reproducible, hence can be applied for routine quality control analysis of cinitapride in pure and pharmaceutical dosage forms.
\end{abstract}

Keywords: Liquid chromatography, Validation, Cinitapride

\section{Introduction}

Cinitapride ${ }^{1-2}$, chemically 4-amino- $N$-[3-(Cyclohexan-1-yl-methyl)-4-piperidinyl]-2-ethoxy5-nitrobenzamide has the molecular formula $\mathrm{C}_{21} \mathrm{H}_{30} \mathrm{~N}_{4} \mathrm{O}_{4}$ and molecular weight $402.49 \mathrm{~g} \cdot \mathrm{mol}^{-1}$. Cinitapride is a drug that has against action to the serotoninergic $5-\mathrm{HT}_{2}$ and $\mathrm{D}_{2}$ dopaminergic 
receptors that has been indicated in the gastro-esophageal reflux and in the functional disorders of gastrointestinal motility treatment. The therapeutic effect of cinitapride lies on the capacity of increasing lower esophageal sphincter tone and has strong gastro kinetic activity, which generates significant increases in the gastric emptiness; besides, through the serotoninergic system it stimulates the intestinal activity. The use of cinitapride is efficient and safe in treatment of patients with disorders in the gastric emptiness related to gastro esophageal reflux and functional dyspepsia as well as in individuals that present irritable bowel syndrome with constipation and abdominal pain. Literature survey reveals a polarographic ${ }^{3}$ method for its determination, a fast, sensitive and selective method for measuring plasma cinitapride using LC-MS/MS with positive ion electrospray ionization using multiple reaction-monitoring (MRM) mode to quantify cinitapride in human plasma using respridone as the internal standard ${ }^{4}$, an RP-HPLC method $^{5}$, and UV spectrophotometric method ${ }^{6}$ for the determination of cinitapride in pharmaceutical formulations is also reported. The target of this study was to develop and validate a new, simple and rapid HPLC method with gradient elution technique for determination of cinitapride in bulk drugs and pharmaceutical formulations.

\section{Experimental}

Cinitapride was kindly supplied by chromo labs, Hyderabad, India. Formic acid and acetonitrile (HPLC grade) were purchased from Merck, Mumbai, India. All other chemicals used were of analytical grade. Double distilled water was used during the entire HPLC procedure.

\section{Chromatographic conditions and instrumentation}

High performance liquid chromatograph was carried out on Shimadzu UFLC prominence with LC20AD quarternary pump, SIL 20 An autosampler and photo diode array detector PDA (SPD-M20A)

The analytical column with $150 \times 4.6 \mathrm{~mm}$ i.d and $5 \mu$ particle size has been optimized to obtain the best possible results. A mixture of $0.1 \%$ formic acid in water (solvent A) and acetonitrile (solvent B) was used as mobile phase. The gradient elution programme has been developed and optimized for better, accurate and consistent results. The gradient programme developed for this method is depicted below.

\begin{tabular}{ccc}
\hline Time, $\min$ & Conc., 'A' & Conc., 'B' \\
\hline 0.01 & 90 & 10 \\
5.00 & 70 & 30 \\
8.00 & 30 & 70 \\
16.00 & 30 & 70 \\
20.00 & 70 & 30 \\
25.00 & 90 & 10 \\
30.00 & 90 & 10 \\
\hline
\end{tabular}

\section{Preparation of standard stock solution}

Accurately weighed $50 \mathrm{mg}$ of cinitapride standard was taken in $100 \mathrm{~mL}$ volumetric flask. This was dissolved in few $\mathrm{mL}$ of methanol and sonicated for five minutes and diluted up to the mark with same solvent to get $500 \mu \mathrm{g} / \mathrm{mL}$ standard stock solution.

\section{Working standard solution}

$2 \mathrm{~mL}$ of he above stock solution was taken in $10 \mathrm{~mL}$ of volumetric flask and made up to the volume with methanol to obtain $100 \mu \mathrm{g} / \mathrm{mL}$ solution Several aliquots of standard stock solutions $0.1,0.25,0.5,1.0$ and $2.0 \mathrm{~mL}$ of cinitapride were taken in different $10 \mathrm{~mL}$ 
volumetric flasks and diluted up to the mark with methanol. Peak area was recorded for all the peaks and calibration graph (Figure $1 \& 2$ ) was obtained by plotting peak area versus concentration of cinitapride. The plot of peak area of each sample against respective concentration of cinitpride was found to be linear in the concentration range of $5-100 \mu \mathrm{g} / \mathrm{mL}$ and the results are furnished in Table 1 . The solutions were injected into the $10 \mu \mathrm{L}$ loop and the chromatogram was recorded as Figure 1

Table 1.Calibration of the proposed HPLC method for the estimation of cinitapride

\begin{tabular}{cc}
\hline Conc. in $\mu \mathrm{g} / \mathrm{mL}$ & Peak area ratio \\
\hline 5 & 344398 \\
12.5 & 812936 \\
25 & 1497830 \\
50 & 2967969 \\
100 & 6473884 \\
\hline
\end{tabular}

Regression equation $y=64143.26 x-43697.86$ (Correlation coefficient $R=0.9987$ )

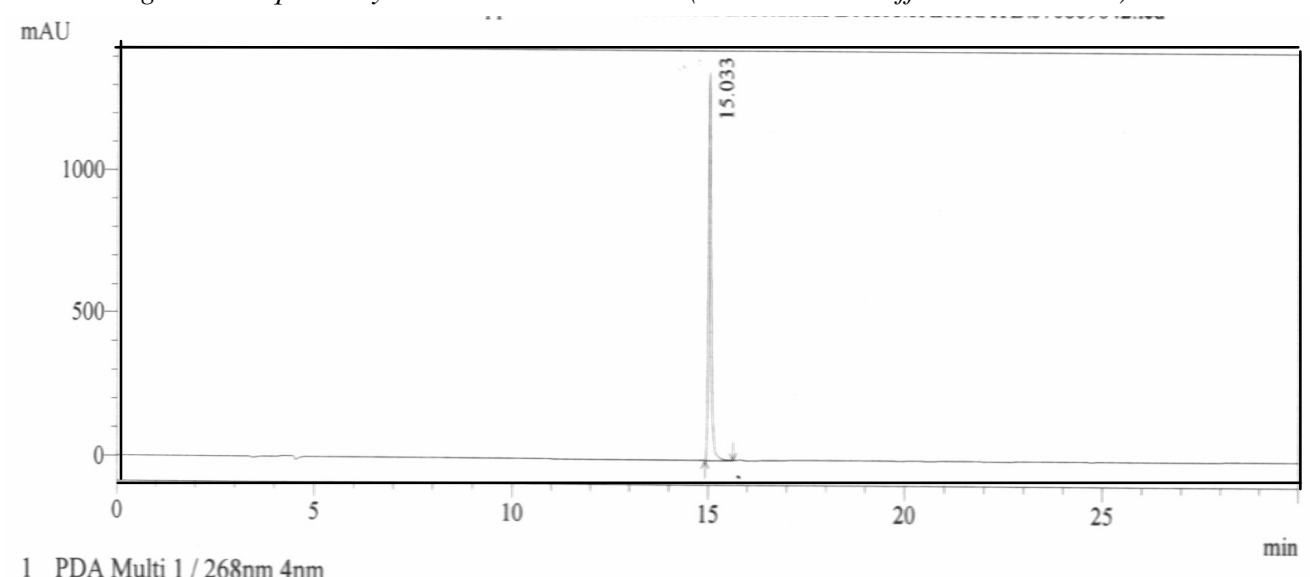

1 PDA Multi $1 / 268 \mathrm{~nm} 4 \mathrm{~nm}$

Figure 1 .Typical chromatogram of cinitapride

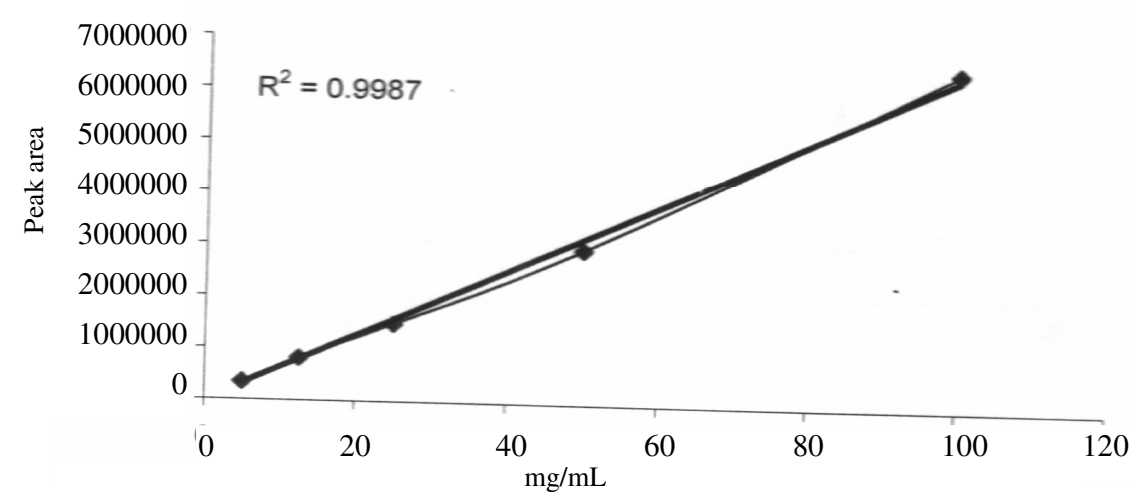

Figure 2. Calibration curve of cinitapride 
Assay

Two commercial brand tablets were chosen for testing suitability of proposed method to estimate cinitapride in pharmaceutical dosage forms. Twenty tablets were weighed accurately and powdered. A quantity equivalent to $50 \mathrm{mg}$ of cinitapride was weighed accurately and transferred to $100 \mathrm{~mL}$ volumetric flask. About $30 \mathrm{~mL}$ of methanol was added and kept in ultrasonic bath for $20 \mathrm{~min}$. This solution is filtered through membrane filter and volume was made up to the mark with methanol to get $500 \mu \mathrm{g} / \mathrm{mL}$ concentration. Solution obtained was diluted with methanol to obtain in the range of linearity previously for the pure drug determined. Sample solution was injected under the chromatographic conditions and chromatogram was recorded. The amount of cinitapride present in the tablet formulation was determined by comparing the peak area from the standard. The results are furnished in Table 2

Table 2.Assay and recovery studies

\begin{tabular}{ccccc}
\hline Formulation & Label claim & Amount found, mg & \%Amount found & \%Recovery \\
\hline Brand -1 & 2.5 & 2.49 & 99.72 & 100.12 \\
Brand-2 & 5.0 & 4.98 & 99.70 & 100.10 \\
\hline
\end{tabular}

\section{Validation of the proposed method}

Selectivity of the method was assessed on the basis of elution of cinitapride using above mentioned chromatographic conditions. To study the specificity, linearity, precision, accuracy, limit of detection, limit of quantitation, robustness and system suitability parameters has been validated for the determination of cinitapride. The results are furnished in Table 3 .

Table 3. System suitability parameters

\begin{tabular}{ccc}
\hline S No & Parameter & Result \\
\hline 1 & Linearity, $\mu \mathrm{g} / \mathrm{mL}$ & $5-100 \mu \mathrm{g} / \mathrm{mL}$ \\
2 & Correlation coefficient & 0.9987 \\
3 & Theoretical plates & 5877 \\
4 & Tailing factor & 0.98 \\
5 & Asymmetry factor & 1.09 \\
6 & LOD,$\mu \mathrm{g} / \mathrm{mL}$ & 0.048 \\
7 & LOQ, $\mu \mathrm{g} / \mathrm{mL}$ & 0.678 \\
8 & Percentage recovery & $98.58-100.24$ \\
\hline
\end{tabular}

\section{Specificity study}

The evaluation of the specificity of the method was determined against a placebo. The interference of the claimed excipients present in the pharmaceutical dosage form was derived using placebo solution.

\section{Linearity}

A 5-point calibration curve was obtained in the concentration range of 5-100 $\mu \mathrm{g} / \mathrm{mL}$ for cinitapride hydrogen tartarate. The peak area versus concentration data were evaluated by linear regression analysis. It was found that correlation coefficient and regression analysis are within the limits. 


\section{Precision}

The method precision has been studied and results obtained for five preparations are tabulated (Table 4) along with calculations for mean, standard deviation and \% relative standard deviation. The system precision was studied by preparing the standard solution at test concentration $i$ e., $100 \mu \mathrm{g} / \mathrm{mL}$ and injected repeatedly for 5 times. The obtained results are shown in Table 5

Table 4. Method precision

\begin{tabular}{cc}
\hline Run & \%Area for cinitapride \\
\hline 1 & 6605666 \\
2 & 6604918 \\
3 & 6642417 \\
4 & 6606552 \\
5 & 6621343 \\
\hline
\end{tabular}

Mean $=6616179.2$, Standard Deviation $=21437.391, \% R S D 0.3239$

Table 5. System precision

\begin{tabular}{cc}
\hline Run & \% Area for cinitapride \\
\hline 1 & 6513992 \\
2 & 6492545 \\
3 & 6611946 \\
4 & 6492343 \\
5 & 6513675 \\
\hline
\end{tabular}

Mean $=6524900.2$, Standard Deviation $=63654.74416, \%$ RSD 0.97

Limit of detection (LOD) and limit of quantitation ( $L O Q)$

The LOD and LOQ for cinitapride were predicted based on the parameters of standard error of estimate and slope, calculated from linearity of the response data of cinitapride.

\section{Accuracy}

An accuracy study was performed by adding known amounts of cinitapride to the sample solution. The actual and measured concentrations were compared. Recovery of the method was evaluated at 3 different concentration levels (corresponding to 50,100 and 150\% of the test preparation concentration). For each concentration level, 3 sets were prepared and injected in duplicate. The results are furnished in Table 6

Table 6. Accuracy studies

\begin{tabular}{lccc}
\hline Description & $150 \%$ & $100 \%$ & $50 \%$ \\
\hline Wt of sample taken & 38.02 & 25 & 12.05 \\
Run 1 (area) & 2279309 & 1519538 & 379884 \\
Run 2 (area) & 2275642 & 1513358 & 387654 \\
Run 3 (area) & 2274352 & 1499869 & 376588 \\
Mean area & 2276434.3 & 1510921 & 381375.3 \\
Std.deviation & 2571.73 & 10058.28 & 5681.73 \\
\%RSD & 0.11 & 0.66 & 1.48 \\
Amount Recovered & 37.67 & 24.42 & 12.15 \\
\%Recovery & 99.07 & 97.68 & 100.82 \\
\hline
\end{tabular}




\section{Results and Discussion}

By applying the proposed method, the retention time of cinitapride in a typical chromatogram was found to be $15.03 \mathrm{~min}$, which indicates a good baseline. Linearity range was observed in concentration of $5-100 \mu \mathrm{g} / \mathrm{mL}$. The regression equation of cinitapride concentration over its peak area ratio was found to be $y=64143.26 x-43697.86(r=0.9987)$. The developed method was validated for precision which includes system precision and method precision. The method is ascertained to be having good reproducibility and repeatability. The \%RSD for method precision was observed to be 0.32 wherein the method precision was observed to be 0.97 . The asymmetry factor was found to be 1.09 , which indicated asymmetry nature of the peak. The number of theoretical plates was found to be 5877 , which indicates efficient performance of the column. The limit of detection and limit of quantitation was found to be 0.048 and 0.678 , indicates the sensitivity of the method. To optimize the chromatographic conditions, various combinations of $0.1 \%$ formic acid in water and acetonitrile were tested. The use of mobile in the ratio 1:1 resulted in peak with good shape and resolution. The high percentage of recovery of cinitapride ranging from 97.68 to 100.82 indicates that the proposed method is highly accurate. No interfering peaks were found in the chromatogram indicating that excipients used in the tablet formulations did not interfere with the estimation of the drug by proposed HPLC method.

\section{Conclusion}

A new analytical method has been developed to be routinely applied to determine cinitapride in its pharmaceutical dosage forms. The results of the study indicate that proposed HPLC method was simple, precise, highly accurate, specific and less time consuming.

\section{Acknowledgment}

The authors are thankful to the Principal, Luqman College of Pharmacy, Gulbarga, Karnataka India, Ogens Analytical Lab, India for providing laboratory facility and chromo labs, Hyderabad, India for supplying the gift sample.

\section{References}

1. O'Neil M J, The Merck Index - An Encyclopaedia of Chemicals, Drugs \& Biologicals, $13^{\text {th }}$ Ed., Merck and Co Inc, Whitehouse Station (NJ, USA), 2006, 2297.

2. Sweetman S C, Inc: Martindale, The Complete drug reference, $35^{\text {th }}$ Ed., London: Pharmaceutical Press; 2002, 1220.

3. Gonzalez M I, Gonzalez P C and Blanco Lopez M.A, Analytica Chimica Acta, 1998, 368(1), 175-181.

4. Shikha Roy M N, Santosh Yetal M, Sangita V Chavan, Varad Pradhan R and Santosh Joshi S, E-J Chem., 2008, 5(3), 453-460.

5. Roy S M N, Kiran V M, Desai A Y and Yetal S M, E-J Chem., 2010,7(1), 311-319.

6. Thangabalan B, Elphine Prabhakar A and Kalaichelvi R, E- J Chem., 2009, 6(S1), S21-S24. 


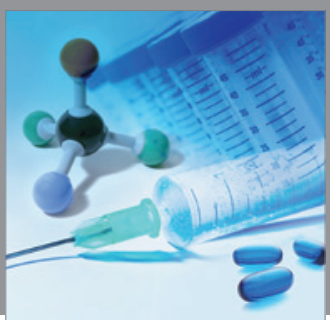

International Journal of

Medicinal Chemistry

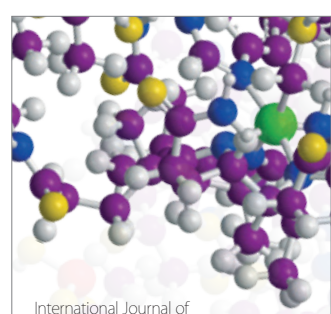

Carbohydrate Chemistry

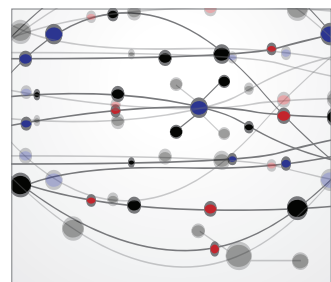

The Scientific World Journal
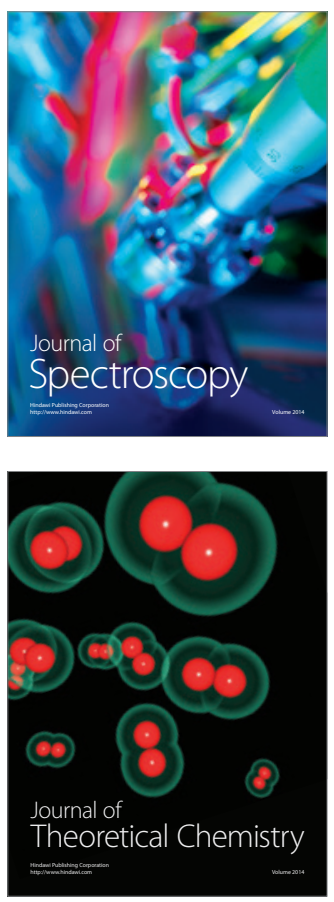
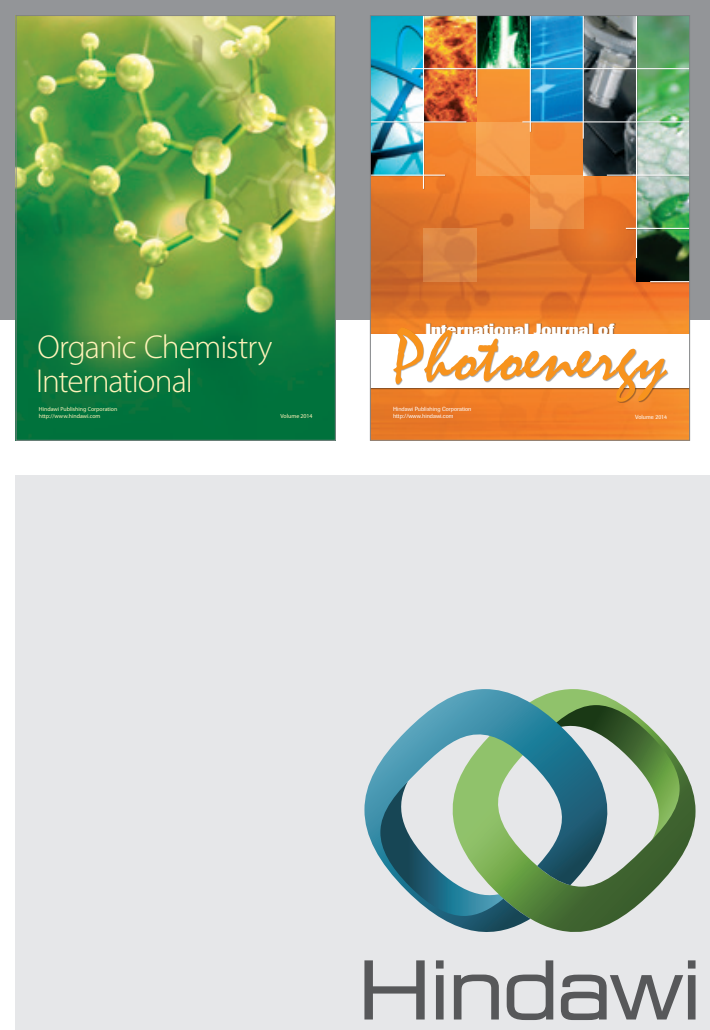

Submit your manuscripts at

http://www.hindawi.com
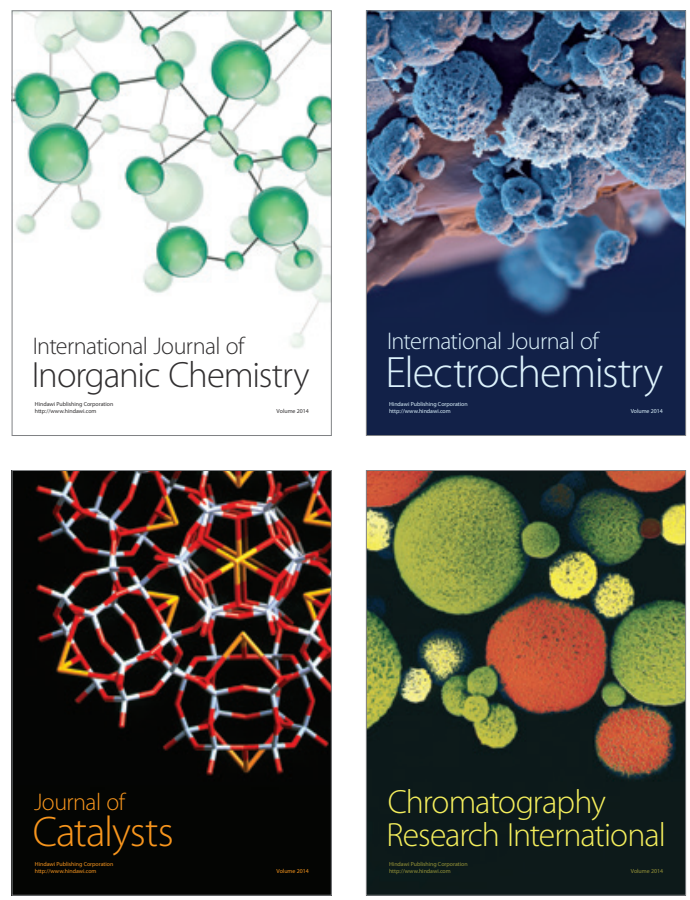
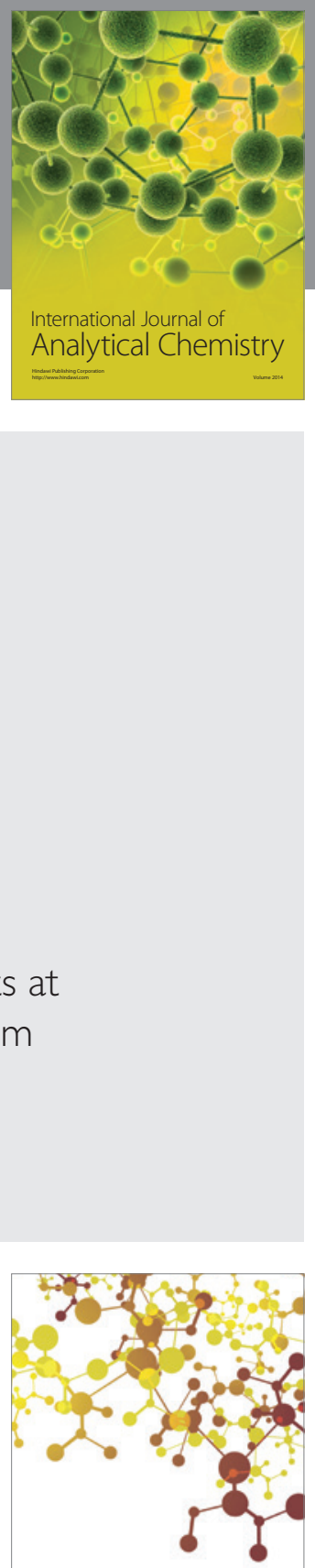

Journal of

Applied Chemistry
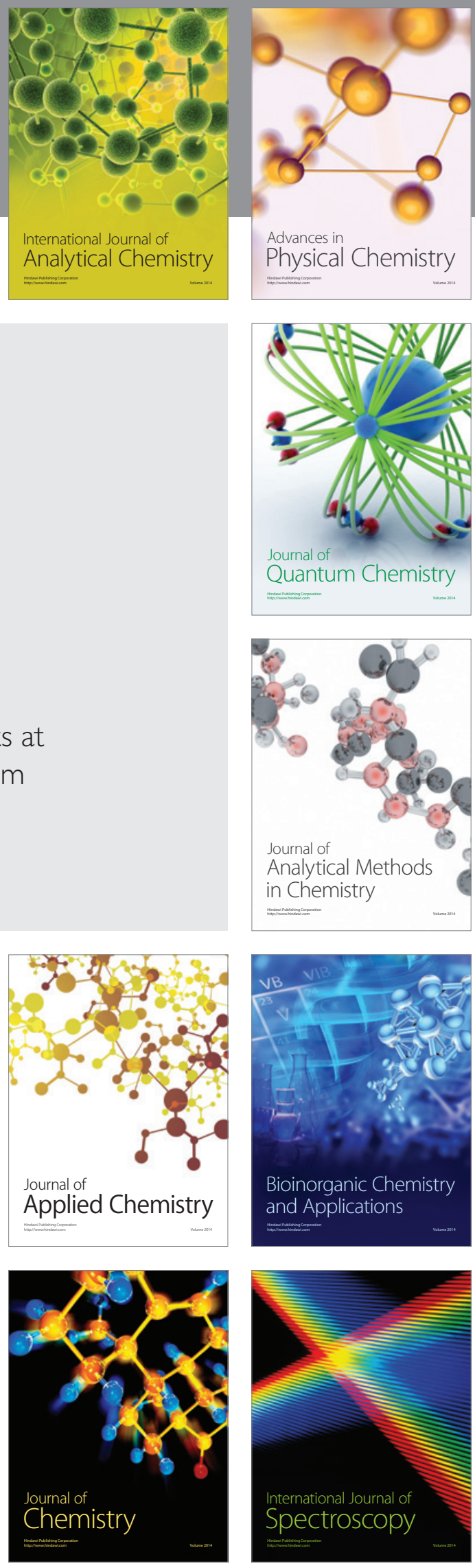